dissolving $25 \mathrm{mg}$ L-cystine-di- $\beta$-naphthylamide in $10 \mathrm{ml}$ hot $0.012 \mathrm{~N}$ hydrochloric acid and adding $10 \mathrm{ml}$. distilled water. The substrate is stable and may be stored at $4^{\circ} \mathrm{C}$. The incubation period lasts $1 \mathrm{~h}$ at room temperature. The final reaction product is diffusely and evenly deposited along the outer margin of the syneytium. Background staining does not occur and sections incubated in the presence of trichloroacetic acid do not show enzyme activity.

The distribution of enzyme activity may reflect oxy. tocinase activity. Alternatively, another enzyme may be hydrolysing $\mathrm{L}$-cystine-di- $\beta$-naphthylamide and the final reaction product represents the localization of this enzyme. Therefore, the trivial name cystino aminopeptidase should not be applied to histochemical activity observed with this substrate, as confusion may result. A similar situation already exists with leucine aminopeptidase (E.C. 3.4.1.1). Leucino aminopeptidase hydrolyses leucineamide more rapidly than L-leucine-di- $\beta$-naphthylamide. At least one other enzyme, however, hydrolyses L-leucine- $\beta$-naphthylamide more rapidly than leucineamide ${ }^{3}$. 'The histochemical activity with respect to leucine- $\beta$-naphthylamide represents a system of enzymes and does not reflect loucine aminopeptidase activity. In addition, the present biochemical nomenclature covering peptide hydrolases is inadequate due to overlapping specificities, and it has been suggested that the trivial names based on particular substrates should be abandoned. The enzyme that hydrolyses the histochemical substrate L-cystine-di- $\beta$ naphthylamide is a cystine-di- $\beta$-naphthylamide hydrolase. If it is shown, however, that this enzyme specifically hydrolyses the cystine-tyrosine bond of oxytocin, then the term oxytocinase may be retained for histochemical use.

Thanks are due to Prof. J. Chassar Moir and Dr. A. H. T. Robb-Smith for the facilities provided for this work.

Department of Pathology,

Nigei T. JAMES*

Radcliffe Infirmary, Oxford.

* Present address: University of Oxford Medical School, Osler House, Woodstock Road, Oxford.

${ }^{1}$ Burstone, M. S., Enzyme Histochemistry and its Application in the Study of Neoplasms (Academic Press, 1962).

2 Pearse, A. E., Histochemistry, Theoretical and Applied (J. and A. Churchill, London, 1960)

${ }^{3}$ Hanson, H., Second Intern. Cong. Histochemistry and Cytochemistry, 113 (Springer-Verlag, 1964)

4 Enzyme Nomenclature, Recommendations (1964) of the International Union of Biochemistry (Elsevier, 1965).

\section{Preferential Staining of Collagen by Acid Dyes in Methanol}

THe effects of dye solvents on the selectivity of histological staining have not been extensively investigated. Robards and Purvis ${ }^{1}$ have reported preferential staining of the gelatinous fibres of tension wood by chlorazol black $E$ when dissolved in methyl cellosolve. Earlier the influence of solvents on the staining reactions of this dye was discussed by Cannon ${ }^{2}$. Puchtler and Sweat ${ }^{3}$ reported a method for selectively staining haemoglobin in sections with amido black in a methanol solution, but not in water. Investigation of phospholipid staining by Luxol fast blue $G$ revealed a changing selectivity dependent on the solvent used ${ }^{4}$. This dye in methanol solution was later found to stain only collagen and elastin ${ }^{5}$.

When other sulphonated acid dyes were later used as methanolic solutions they preferentially stained connective tissue elements. This selective staining did not occur with aqueous solutions of the dyes. Among the dyes successfully used in this manner were acid fuchsin, aniline blue, methyl blue, fast green $F C F$, chlorazol black $E$, and pontamine fast turquoiso $8 G L S$. Most of these dyes also selectively stain collagen when used as mixtures in saturated picric solutions, such as the Van Gieson stain.

Methylation, nitrosation and acetylation of tissue sections did not prevent the selective staining ${ }^{5}$. The staining was reduced by tanning with tannic acid, which affects the physical nature of collagen by the introduction of cross-linkages. Although the mechanism of this collagen staining has not been finally elucidated, it would seem to be of a physical nature rather than an affinity for specific chemical groupings in the collagen macromolecule.

It was considered that the most likely explanation for the preferential staining was a difference in the type of micelle or molecular arrangement of the dyes in methanol and water. The molecular form of the dye in methanol might conceivably have a greater affinity for collagen. However, as the molecular arrangement of the dyes in the two solutions appears to be comparable when examined in the analytical ultracentrifuge ${ }^{6}$, this explanation is unlikely. It may be that methanol affects the permeability of the various proteins present in tissue sections, allowing only the collagen to stain. Collagen has a maximum solvation coefficient of $218 \mathrm{~g} / \mathrm{g}$, which is much higher than that for other non-globular protein polymers likely to be present in mammalian tissue sections, such as myosin $(49 \mathrm{~g} / \mathrm{g})$ and tropomyosin $(23 \mathrm{~g} / \mathrm{g})^{7}$; possibly this particular property of collagen is associated in some manner with its preferential staining.

As the collagen-staining reaction can be used after other histochemical and staining procedures in which the dyes used are not removable by methanol, it may be of value in histochemical investigations of connective tissue.

I thank Dr. Joel Kirschbaum of this Institute for examining the dye solutions in the analytical ultracentrifuge.

\section{T. N. Salthouse}

Department of Pathology,

The Squibb Institute for Medical Rescarch, New Brunswick, New Jersey.

${ }^{1}$ Robards, A. W., and Purvis, M. J., Stain Tech., 39, 309 (1964).

${ }^{2}$ Cannon, H. G., J. Roy. Micros. Soc., 61, 88 (1941).

${ }^{3}$ Puchtler, H., and Sweat, F., J. Histochem. Cytochem., 12, 900 (1964).

4 Salthouse, 'T. N., Nature, 199, 821 (1963).

Salthouse, T. N., J. Histochem. Cytochem., 13, 133 (1965).

' Kirschbaum, J. (personal communication).

" Tanford, C., Physical Chemistry of Macromolecules (John Wiley and Sons inc., Ncw York, 1963).

\section{Histochemical Distribution of Alcohol Dehydrogenases in Endocrine Tissue}

Histochemical investigations of alcohol dohydrogenase in rodents using various alcohols ${ }^{1}$ revealed no obvious differences in the sites of alcohol utilization. Primary and secondary alcohols in general tissues were utilized at the same sites; the present communication deals with the histochemical variations in sites of utilization of different alcohols in steroid-producing endocrine glands.

Human term placenta, obtained at Caeserean section, and rat (Royal Wistar) adrenal glends, tostes and ovaries were frozen on solid earbon dioxide and the ticstics were prepared and incubated as described by Ferguson ${ }^{1}$, using the following alcohols (final concentration 2.5 per cent): methanol, ethanol, propanol, butanol, pentanol, hexanol, heptanol, octanol, nonanol, decanol, undecanol, dodecanol, tridecanol, phenol, hydroquinone, 2-ethoxyethanol, allyl alcohol, 2-methyl-butan-1-ol, 3-methyl-butan-1-ol, nonyl alcohol, tortiary butanol, tertiary butyl carbinol, isopropanol, secondary butanol, pentan-2-ol, pentan-3-ol, octan-2-ol, cyclohexanol, ethylene glycol, propylene glycol, glycerol, butan-1 : 3-diol, butœn-1 : 4-diol, pinacol and furfuryl alcohol.

Control sections were concurrently incubated in the buffered medium containing no alcohol.

The results are summarized in Table 1.

Sinco Bonnichsen ${ }^{2}$ isolated alcohol dehydrogen£se from horse liver, the biochemical properties and mechanism of action of this enzyme have been widely described ${ }^{3-14}$. 